REVISTA DE DERECHO UNED, NÚM. 24, 2019

\title{
PROCEDIMIENTO ADMINISTRATIVO EN VÍA DE REGRESO: CONSIDERACIONES SOBRE SU (IN)APLICACIÓN PRÁCTICA EN EL ÁMBITO DE LA ENSEÑANZA PÚBLICA
}

ADMINISTRATIVE PROCEDURE ON THE ROAD OF RETURNS: CONSIDERATIONS ON YOUR (IN)PRACTICAL APPLICATION IN THE FIELD OF PUBLIC EDUCATION

\author{
Carmen Delgado Moral \\ Profesora de Educación Secundaria \\ Licenciada en Filología Hispánica \\ y Doctora por la Universidad de Córdoba \\ Graduada en Derecho por la UNED
}

Resumen: El presente artículo analiza la exigencia normativa referida al procedimiento administrativo en vía de regreso sobre los docentes cuando estos incurren en dolo, culpa o negligencia graves en el ejercicio de su labor y como consecuencia de ello se produce un daño antijurídico a un tercero, del que se deriva una responsabilidad patrimonial de la Administración Pública. Se analizan los requisitos para el ejercicio de la acción de repetición de la Administración sobre el personal a su servicio y se reflexiona sobre los motivos que pudieran motivar lo que en la actualidad se ha convertido en una manifiesta inaplicación práctica de una norma administrativa en general, y en el ámbito de la enseñanza pública en particular.

Palabras clave: acción de regreso, enseñanza pública, responsabilidad patrimonial, indemnización, dolo, culpa, negligencia grave.

Abstract: This article analyzes the normative requirement referred to the administrative procedure in way of return on the tea- 
chers when they commit serious fraud, fault or negligence in the exercise of their work and as a consequence there is an unlawful damage to a third party, of which a patrimonial responsibility of the Public Administration is derived. The requirements for the exercise of the action of repetition of the Administration on the staff at its service are analyzed and the reasons that might motivate what at present has become a manifest practical non-application of an administrative rule in general are analyzed and in the field of public education in particular.

Keywords: return action, public education, patrimonial responsibility, compensation, fraud, fault, gross negligence.

Recepción original: 29/12/2018

Aceptación original: 31/01/2019

Sumario: I. Introducción. II. La acción de repetición: desde sus orígenes a la actualidad. II. 1. Fundamento de la acción de repetición. II. 2. Configuración actual de la acción de repetición. III. Requisitos para su ejercicio. IV. Consideraciones sobre su aplicación práctica. V. Reflexión sobre lo justo de su (in)aplicación. VI. Actuación versus inactividad administrativa: una propuesta de armonización. VII. Conclusiones.

\section{INTRODUCCIÓN}

La aplicación de la acción de regreso en el Derecho español no es que se considere una rara avis, sino que ha devenido en una manifiesta consumación de inaplicación de una norma válida, osado escollo para la credibilidad de nuestro sistema administrativo, a excepción de leves manifestaciones en el ámbito de la sanidad y el orden público y que dejaremos al margen, por no ser el propósito del presente estudio. Con ingenioso tono humorístico, Díez Sánchez la denominó «bonito florero» ${ }^{1}$, en el sentido en el que la norma pretende dar una apariencia de buen gobierno en esta era de la transparencia y la eficiencia ${ }^{2}$ a lo que no deja de ser una mera norma ornamental

${ }^{1}$ DÍEZ SÁNCHEZ, J.J., «Las acciones de regreso contra autoridades y funcionarios públicos», en La responsabilidad civil y su problemática actual (coord. Antonio Moreno Martínez), Madrid, Dykinson, 2007, pág. 216.

2 SAURA FRUCTUOSO, C., «La ignota acción de regreso de la administración en la era de la transparencia, la eficiencia y la responsabilidad, La ignota acción de regreso de la administración en la era de la transparencia, la eficiencia y la responsabilidad», Documentación Administrativa: Nueva Época, 2 (2015). 
que tiene como eje de responsabilidad nada menos que la propia Administración.

Es frecuente utilizar las expresiones acción de regreso y acción de repetición como sinónimas, pero cabe preguntarse si ambas son correctas o cuál es la más adecuada. El diccionario de la Real Academia Española define repetición para el ámbito del derecho como la «acción de quien ha sido desposeído, obligado o condenado, contra tercera persona que haya de reintegrarle o responderle». No define, en cambio, para este ámbito, el término regreso, por lo que este no tendría otro significado que el genérico de «devolver o restituir algo a su poseedor». En este sentido, Rosa Collado defiende la postura - que compartimos- de que resulta más ajustado «utilizar la expresión acción de repetición, ya que las Administraciones no regresan frente a anteriores obligados, sino que repiten frente a ellos una vez que han sido identificados, lo que sucede en cuatro supuestos» ${ }^{3}$, uno de los cuales es el que aquí nos interesa: «cuando el servicio público ha funcionado de modo anormal por culpa o negligencia de los funcionarios gestores del mismo». Para ello previamente ha debido ejercitarse una acción de responsabilidad contra la Administración por parte de un particular, basada aquella en un concepto de lesión (física o psíquica), y que esta, siempre y cuando el tercero no tenga el deber jurídico de soportar, haya sido evaluada como un daño efectivo, real, evaluable económicamente e individualizado y, por ello, haya dado lugar a una indemnización por parte de la Administración; solo en este caso pudiera darse la acción de repetición sobre el funcionario. Por ello, pues, puede afirmarse que la acción de repetición solo existe si se da la acción de responsabilidad de la Administración, pero no toda acción de responsabilidad por parte de aquella da lugar a la acción de repetición de esta hacia el funcionario.

\section{LA ACCIÓN DE REPETICIÓN: DESDE SUS ORÍGENES A LA ACTUALIDAD}

\section{II.1. Fundamento de la acción de repetición}

Desde sus inicios, la acción de repetición se configuró como un ejercicio dispositivo, discrecional por parte de la Administra-

3 COLLADO MARTÍNEZ, R., "Algunas notas sobre la responsabilidad patrimonial en las Leyes 39/2015, de 1 de octubre, del Procedimiento Administrativo Común de las Administraciones Públicas y 40/2015, de 1 de octubre, de Régimen Jurídico del Sector Público», Asamblea: revista parlamentaria de la Asamblea de Madrid, 34 (2016), 155-196, espec. pág. 163.

(C) UNED. Revista de Derecho UNED, núm. 24, 2019 
ción y acumulable junto con la responsabilidad disciplinaria y/o penal. Sin detenernos en el Texto articulado de la Ley de Régimen Local publicado en 1950, o en la Ley de Expropiación Forzosa, entre otras normativas que la configuran, queremos hacer mención a la Ley 30/1992, de 26 de noviembre, de Régimen Jurídico de las Administraciones Públicas y del Procedimiento Administrativo Común. El artículo 145.2. de la redacción originaria establecía que «La Administración correspondiente, cuando hubiere indemnizado directamente a los lesionados, podrá exigir de sus autoridades y demás personal a su servicio la responsabilidad en que hubieran incurrido por dolo, culpa o negligencia grave, previa la instrucción del procedimiento que reglamentariamente se establezca», de lo que se colige su carácter discrecional. Posteriormente, y tras la reforma operada por la Ley 4/1999, de modificación de la Ley 30/1992, de 26 de noviembre, de Régimen Jurídico de las Administraciones Públicas y del Procedimiento Administrativo Común, se pretende garantizar la efectividad de la responsabilidad patrimonial de las autoridades y personal al servicio de las Administraciones Públicas mediante su exigencia de oficio; en este sentido, el artículo 145.2 de la mencionada ley establecía lo siguiente:

"La Administración correspondiente, cuando hubiere indemnizado a los lesionados, exigirá de oficio de sus autoridades y demás personal a su servicio la responsabilidad en que hubieran incurrido por dolo, o culpa o negligencia graves, previa instrucción del procedimiento que reglamentariamente se establezca.

Para la exigencia de dicha responsabilidad se ponderarán, entre otros, los siguientes criterios: el resultado dañoso producido, la existencia o no de intencionalidad, la responsabilidad profesional del personal al servicio de las Administraciones públicas y su relación con la producción del resultado dañoso».

Se pasa, pues, de una exigencia de responsabilidad potestativa («podrá exigir», forma perifrástica con valor de posibilidad, empleada en la Ley 30/1992), que, como manifiesta Beatriz Díaz, se traducía en un uso excepcional por parte de la Administración ${ }^{4}$, a una preceptiva (el «exigirá», futuro con valor imperativo, luego reproducido por la Ley 40/2015, de 1 de octubre, de Régimen Jurídico del Sector Público), a la que se añade además la actuación «de oficio» por parte de la Administración, esto es, sin que medie solicitud de parte. Se trataba - como bien apuntó el Consejo de Estado en el Dictamen de 22 de enero de 1998-, de «dar efectividad

${ }^{4}$ DÍAZ MADRERA, B., La responsabilidad patrimonial de la Administración en el ámbito educativo, Madrid, Reus, 2007, pág. 53, nota 45. 
a una previsión legal que prácticamente no se ha aplicado» ${ }^{5}$. Sin embargo, el segundo párrafo de dicho artículo no determina la relevancia prevista para cada uno de los resultados o acciones que se vinculan a la ponderación establecida, por lo que regresamos de nuevo al principio, por la indeterminación expresada por el artículo. Quizá esta sea una de las razones por las que la acción de repetición se ha caracterizado por su falta de ejercicio, y concretamente en el ámbito que nos ocupa en este artículo, la Administración educativa, nunca se ha ejercido, lo que ha provocado que exista una proliferación doctrinal en contra de su inaplicación. En este sentido, David Blanquer opina que en un Estado social y democrático de Derecho no cabe «la consagración de la inmunidad de las autoridades y funcionarios públicos. Los ciudadanos y empresas o administraciones privadas que incumplen los dictados legislativos deben sufrir las consecuencias desfavorables de su infracción. Lo mismo debe suceder con las autoridades y funcionarios públicos, pues de lo contrario se sientan las bases para debilitar y falsear la vigencia práctica y efectiva del principio de legalidad dispuesto en la Constitución» ${ }^{6}$. Quizá sea esta una postura extremada, en tanto que se pretende aplicar al sector público las pautas de actuación de agentes económicos privados, lo que a todas luces se reconocería como inviable en nuestro actual sistema. En la misma dirección se pronunciaba Javier Barcelona: «Me parece obvio que las arcas públicas no tienen por qué soportar íntegramente y en solitario todas las indemnizaciones a que los ciudadanos tienen derecho, que en ciertas ocasiones es preciso involucrar el patrimonio del agente causante del daño, que no hay razón para que los presupuestos públicos asuman totalmente el coste resarcitorio de determinados comportamientos ${ }^{7}$; igualmente Díez Sánchez apunta que «La responsabilidad directa y exclusiva de la Administración Pública no puede concebirse, en efecto, como una patente de corso garantista hacia el exterior y exenta de consecuencias hacia el interior» ${ }^{8}$. Es opinión mayoritaria el que las conduc-

${ }^{5}$ Consejo de Estado. Dictamen de Consejo de Estado n. ${ }^{\circ}$ 5356/1998 de 22 de enero de 1998, sobre «Anteproyecto de Ley de Modificación de la Ley 30/92, 26 de noviembre, de régimen jurídico de las Administraciones Públicas y del procedimiento administrativo común», art. 145.

${ }^{6}$ BLANQUER, D., La responsabilidad patrimonial de las Administraciones Públicas, Madrid, Instituto Nacional de Administración Pública, 1997, pág. 119.

7 BARCELONA LLOP, J., "La acción de regreso en la Ley de Régimen Jurídico de las administraciones públicas y del procedimiento administrativo común», en VV.AA., Homenaje a Luis Rojo Ajoria: escritos jurídicos, Universidad de Cantabria, 2003, págs. 765-784, espec. pág. 767.

8 DÍEZ SÁNCHEZ, J.J., art. cit., pág. 213.

(C) UNED. Revista de Derecho UNED, núm. 24, 2019 
tas negligentes ocasionadas por funcionarios y empleados públicos en el ejercicio de sus funciones no deben ser indemnizadas por la Administración en perjuicio de la Hacienda Pública, o lo que es lo mismo, la ciudadanía en general; pese a ello, la Administración Pública continúa indemnizando a los particulares por las conductas negligentes del funcionariado, lo cual confirma aquella tesis de Lucas Beltrán ${ }^{9}$ cuando definía el sector privado como la parte del sistema que era controlado por el Gobierno, en tanto que el sector público nadie lo controlaba.

El comportamiento de los funcionarios ya fue analizado en 1971 por William A. Niskanen, quien llegó a la conclusión de que aquel era una de las causas del aumento del gasto público. Con la inaplicación de la acción de repetición volvemos a la misma idea, pues la sociedad puede calificar el comportamiento de la Administración Pública hacia el personal a su servicio como indolente, por la inaplicación de mecanismos sancionadores que contribuyen a que se reiteren determinados tipos de conductas, que serían penalizadas en cualquier otro ámbito.

\section{II.2. Configuración actual de la acción de repetición}

El capítulo IV de la Ley 40/2015, de 1 de octubre, de Régimen Jurídico del Sector Público, reproduce los principios de la responsabilidad patrimonial de las Administraciones Públicas y de las autoridades y demás personal a su servicio que ya inaugurara la Ley $30 / 1992$, de 26 de noviembre; la nueva ley dispone que «los particulares tendrán derecho a ser indemnizados por las Administraciones Públicas correspondientes, de toda lesión que sufran en cualquiera de sus bienes y derechos, siempre que la lesión sea consecuencia del funcionamiento normal o anormal de los servicios públicos salvo en los casos de fuerza mayor o de daños que el particular tenga el deber jurídico de soportar de acuerdo con la Ley» (art. 32). Los particulares que hayan sufrido una lesión, bien por el funcionamiento normal o anormal del servicio público, deberán dirigir su reclamación de indemnización directamente contra la Administración, y no contra el empleado público subjetivamente responsable del daño, lo cual no impide la exigencia a este de una responsabilidad penal cuando se trate de conductas que estén tipificadas en el Código Penal. Por tanto, no es objeto de ese procedimiento del par-

9 Vid. BELTRÁN FLORES, L., "¿Crecimiento indefinido del Sector Público?», Papeles de economía española, 7 (1981), 130-135. 
ticular perjudicado contra la Administración la identificación del empleado público causante del daño que ha originado la responsabilidad administrativa, y mucho menos si existió dolo, culpa o negligencia graves por parte de aquel, lo cual tendría lugar en una etapa posterior de reclamación de la Administración contra aquél en una acción de repetición, en tanto que lo que se sustancia en un procedimiento de estas características es si existe una responsabilidad objetiva por parte de la Administración.

La actual Ley 40/2015 da una nueva redacción a la acción de repetición en su artículo 36.2:

«La Administración correspondiente, cuando hubiere indemnizado a los lesionados, exigirá de oficio en vía administrativa de sus autoridades y demás personal a su servicio la responsabilidad en que hubieran incurrido por dolo, o culpa o negligencia graves, previa instrucción del correspondiente procedimiento.

Para la exigencia de dicha responsabilidad y, en su caso, para su cuantificación, se ponderarán, entre otros, los siguientes criterios: el resultado dañoso producido, el grado de culpabilidad, la responsabilidad profesional del personal al servicio de las Administraciones públicas y su relación con la producción del resultado dañoso».

El apartado 3 del referido artículo indica que «Asimismo, la Administración instruirá igual procedimiento a las autoridades y demás personal a su servicio por los daños y perjuicios causados en sus bienes o derechos cuando hubiera concurrido dolo, o culpa o negligencia graves».

El citado artículo está incluido en el capítulo IV intitulado «De la responsabilidad patrimonial de las Administraciones Públicas», de ahí que para que la Administración pueda ejercitar dicha acción previamente un particular ha debido sufrir una lesión debida a un funcionamiento normal o anormal del servicio público, siempre que no sea ocasionado por una fuerza mayor, y siempre que no tenga el deber jurídico de soportar, y dicho particular ha debido solicitar una indemnización a la Administración en la que ha debido especificar «las lesiones producidas, la presunta relación de causalidad entre éstas y el funcionamiento del servicio público, la evaluación económica de la responsabilidad patrimonial, si fuera posible, y el momento en que la lesión efectivamente se produjo», según lo establecido en el artículo 67.2 de la Ley 39/2015, de 1 de octubre, del Procedimiento Administrativo Común de las Administraciones Públicas.

Los artículos 32 y 36 de la mencionada Ley 40/2015 atienden a dos momentos y acciones diferenciadas, no siendo necesario en el 
procedimiento de acción de repetición de la Administración contra el personal a su servicio que el daño subjetivo producido por este haya sido objeto de enjuiciamiento en un procedimiento anterior, según queda acreditado en la Sentencia de Tribunal Constitucional 15/2016, de 1 de febrero de 2016 ${ }^{10}$ : "no es condición de la segunda acción, o de regreso, que la acción u omisión dañosa, el dolo, culpa o negligencia graves, potencialmente imputables a un concreto empleado público, fueran objeto de enjuiciamiento, ni de declaración probatoria como causante del perjuicio, en el primer proceso de responsabilidad objetiva de la Administración» (Fundamento jurídico tercero).

El ejercicio de la acción de regreso presupone la existencia de los siguientes requisitos:

1. La existencia de un procedimiento que establezca la obligación de la Administración de indemnizar a un tercero, en tanto que se ha producido un daño antijurídico que sea imputable a aquella, dada una relación de causalidad directa y eficaz entre el hecho acaecido y el daño.

2. El establecimiento de una cantidad indemnizatoria por parte de la Administración.

3. Que como resultado de la instrucción del procedimiento administrativo correspondiente se haya concluido que ha existido dolo, culpa o negligencia graves por parte del personal al servicio de la Administración.

Sorprendentemente la norma no indica el plazo del que dispone la Administración para ejercitar la acción de repetición, pero puesto que en las solicitudes de iniciación en los procedimientos de responsabilidad patrimonial establecidos en el artículo 67 de la Ley 39/2015, del Procedimiento Administrativo Común de las Administraciones Públicas el interesado dispone del plazo de un año para ejercer su derecho a solicitar el inicio de un procedimiento de responsabilidad patrimonial desde que se haya producido el hecho o el acto que motivó la solicitud de indemnización, debe entenderse que la Administración dispone del mismo plazo de un año para ejercer la acción de repetición contra el personal a su servicio. Según lo establecido en el citado artículo: «En caso de daños de carácter físico o psíquico a las personas, el plazo empezará a computarse desde la curación o la determinación del alcance de las secuelas».

${ }^{10}$ BOE núm. 57, de 7 de marzo de 2016. 
La actual redacción, pues, regula la exigencia de oficio. Sin embargo, pese al mandato expresado por la forma verbal «exigirá», hasta el momento la Administración no ha ejercido dicha acción de repetición en el campo de la responsabilidad patrimonial de la Administración en los centros educativos, careciendo, por tanto, de una utilidad práctica.

El artículo 62 de la Ley 39/2015 precisa el «inicio del procedimiento por denuncia» por parte de cualquier persona, especificando en su apartado tercero que «cuando la denuncia invocara un perjuicio en el patrimonio de las Administraciones Públicas la no iniciación del procedimiento deberá ser motivada y se notificará a los denunciantes la decisión de si se ha iniciado o no el procedimiento». Se pretende utilizar, pues, la delación por parte del ciudadano para la aplicación de una acción contra el funcionario que es resultado de una conducta dolosa, culposa o negligente, mostrando de esta manera la Administración su propia incapacidad, o negligencia, para iniciar de oficio una actuación que está contenida en la propia norma.

El artículo 36.4 de la citada Ley 40/2015 establece que el procedimiento para la exigencia de la responsabilidad referida anteriormente se sustanciará conforme a lo dispuesto en la Ley 39/2015, iniciándose a instancias del órgano competente, con notificación a los interesados. Dicho procedimiento constará, al menos, de los siguientes trámites:

«a) Alegaciones durante un plazo de quince días.

b) Práctica de las pruebas admitidas y cualesquiera otras que el órgano competente estime oportunas durante un plazo de quince días.

c) Audiencia durante un plazo de diez días.

d) Formulación de la propuesta de resolución en un plazo de cinco días a contar desde la finalización del trámite de audiencia.

e) Resolución por el órgano competente en el plazo de cinco días».

La mencionada ley también establece que «La resolución declaratoria de responsabilidad pondrá fin a la vía administrativa» (art. 36.5).

Debemos tener en cuenta que la finalidad de esta acción de repetición no es que la víctima del daño sea resarcida, puesto que la Administración ya ha hecho frente a la indemnización correspondiente; la finalidad perseguida es doble: por un lado, que la Administración no deba avalar las imprudencias del personal a su servicio (solo en los casos en los que se haya incurrido en dolo, culpa o ne- 
gligencia graves), en una conducta casi épica de salvaguarda del patrimonio público y los intereses generales, que queda recogida en el artículo 103 de nuestro texto constitucional: «La Administración Pública sirve con objetividad los intereses generales y actúa de acuerdo con los principios de eficacia (...) con sometimiento pleno a la ley y al Derecho»; y por otro, que la conducta de la autoridad o el funcionario causante del daño no quede impune, puesto que de esta manera el resto del personal no tendría ningún incentivo para tratar de evitar conductas que pudieran generar un daño o un perjuicio para los administrados.

El hecho de aplicar la acción de repetición tendría una función preventiva, en tanto que las conductas dolosas o gravemente culposas que hayan sido objeto de la misma podrían verse como exemplum ex contrario. No estamos hablando de equivocaciones, desconocimientos, comportamientos ineptos, imprudencias inconscientes, despistes, descuidos e incluso negligencias (siempre que no sean graves), que un docente pudiera realizar en su práctica diaria con el alumnado, bien sea en el ejercicio de actividades escolares, complementarias o extraescolares, sino que hablamos de conductas realizadas de forma intencionada (dolo), en las que existe una conciencia de la antijuricidad de una determinada conducta, o bien en las que media la culpa o la negligencia graves. Según ya enunció R. Frank en su obra Sobre la estructura del concepto de culpabilidad, la «culpabilidad es reprochabilidad» de una conducta antijurídica ${ }^{11}$; existe, pues, la conciencia de la contrariedad de un deber por parte de un sujeto, de lo que se deriva el reproche a una determinada conducta provocada bien por acción, bien por omisión.

\section{REQUISITOS PARA SU EJERCICIO}

Como se ha señalado anteriormente, para que pueda activarse esta acción de repetición contra un docente, son necesarios una serie de requisitos. En primer lugar, que el procedimiento principal haya finalizado. En segundo lugar, que el particular que sufrió la lesión haya sido indemnizado. Y finalmente, que la autoridad, agente o funcionario público haya actuado con dolo, culpa o negligencia graves. Quedan excluidos, pues, los daños causados por culpa o negligencia leve o levísima, que se imputarían a la Administración, la cual tiene como arma frente al personal a su servicio la potestad disciplinaria.

${ }^{11}$ FRANK, R., Sobre la estructura del concepto de culpabilidad, Montevideo-Buenos Aires, Editorial B de f, 2002, pág. 39. 
Uno de los principales problemas se halla en la dificultad para discernir el dolo de la culpa. Para el caso del dolo, nos estaríamos adentrando en el iter criminis, cuya fase interna es claramente impune, al no poderse castigar ni la deliberación interna del sujeto ni la resolución de acometer una determinada acción penada por el derecho. En cuanto a su fase externa, es necesario definir los actos preparatorios y ejecutivos, así como tener en cuenta cualquier tipo de causa de justificación, a saber: la legítima defensa, el estado de necesidad, el cumplimiento de un deber o ejercicio legítimo de un derecho y el consentimiento. La concurrencia de causas de justificación determinaría el desvalor del hecho, de lo que se derivaría la falta de tipicidad como fundamento de lo injusto de una determinada conducta.

Por otro lado, para medir el grado de culpabilidad al que se refiere la norma, se debe tener en cuenta las condiciones concretas en las que ha acaecido la acción u omisión que dio lugar a un hecho contrario al derecho. Para ello es necesario, en primer lugar, analizar las circunstancias en las que esa determinada acción u omisión ha tenido lugar, y por otro valorar si el sujeto podría o no haber actuado de otra determinada manera antes de decidir si su conducta puede calificarse o no como reprobable, lo cual se adentra ya en un ámbito valorativo que comporta la observación de la singularidad del concreto sujeto, lo que determina la dificultad práctica de un juicio objetivo de reprochabilidad como fundamento de la culpabilidad; en palabras de Diego-Manuel Luzón, «la reprochabilidad jurídica-penal individual se basa en la libertad de decisión y actuación del sujeto", así como en "su posibilidad de acceder a las normas y de determinarse normalmente por ellas» ${ }^{12}$. De cualquier forma, estamos en el campo de la imputación subjetiva, que se consagra en nuestro Código Penal cuando sentencia que «No hay pena sin dolo o imprudencia» (art. 5).

Debemos tener presente que para que exista dolo debe haber una intención consciente por parte de un sujeto de realizar una determinada conducta antijurídica incardinada en un tipo objetivo y que lo circunscribe como elemento subjetivo de lo injusto. El dolo exige que el autor tenga consciencia de la peligrosidad de su conducta, así como de la relación de causalidad entre dicha conducta y un determinado resultado, es decir, que el sujeto decide realizar una determinada conducta a sabiendas de que la misma es antijurídica. Por ejemplo, un docente ha causado una lesión a un alumno de Educa-

12 LUZÓN PEÑA, D.M., "Libertad, culpabilidad y neurociencias», Indret: Revista para el Análisis del Derecho, 3 (2012), 1-59, espec. p. 32.

(C) UNED. Revista de Derecho UNED, núm. 24, 2019 
ción Secundaria Obligatoria al imponer una medida disciplinaria contraria a la integridad física del menor, actuación que ha derivado en la solicitud por parte de sus padres de una indemnización a la Administración educativa por daños y perjuicios; obviamente existe un conocimiento por parte del docente de la ilicitud de su conducta pues, aunque no tuviera un conocimiento exacto del contenido del artículo 31.2.b) del Decreto 327/2010, de 13 de julio, por el que se aprueba el Reglamento Orgánico de los Institutos de Educación Secundaria, al menos debe conocer que se trata de una conducta desaprobada en numerosas normas de nuestro ordenamiento jurídico, en tanto que atenta contra uno de los derechos fundamentales, como es el derecho a la protección física. Por tanto, en este caso estaría justificado el inicio de la acción de repetición hacia el docente, siempre y cuando la Administración haya procedido a la indemnización correspondiente al perjudicado. Pongamos otro ejemplo en el que no existe dolo, aunque sí imprudencia grave: es el caso de un docente que realiza una actividad extraescolar consistente en una ruta en bicicleta con alumnos menores de edad; al finalizar la actividad el docente vuelve con sus alumnos al centro sin haberse cerciorado de que no ha quedado ningún alumno separado del grupo; ha considerado probable que su conducta sea negligente, pese a lo cual la realiza. Nadie se da cuenta de que un alumno, que además posee un trastorno del espectro autista, no ha vuelto al centro, siendo el profesor conocedor de esta circunstancia tras recibir una llamada de los padres del alumno al centro informando de que su hijo se encuentra hospitalizado tras haber sufrido un desafortunado accidente con la bicicleta mientras realizaba la referida actividad. El docente claramente ha incumplido su deber de cuidado del menor, habiendo actuado con imprudencia, al no haber obrado con la diligencia propia de un buen padre de familia para prevenir el daño.

Sin embargo, como bien indica Paz M. de la Cuesta, cuando se trata de averiguar si un determinado autor era conocedor de la ilicitud de una conducta debe tenerse en cuenta igualmente qué incidencia tuvo ese conocimiento en la decisión adoptada por el mismo ${ }^{13}$, lo que no resulta en principio tarea nada fácil. En este aspecto resulta esencial que el docente conozca unas normas básicas que puedan ayudarle a un mejor desarrollo de su profesión, como pueden ser, por ejemplo, los derechos y deberes del alumnado, la normativa referente a protección de datos, a primeros auxilios, a propiedad inte-

13 CUESTA AGUADO, P. M. de la, Conocimiento de la ilicitud. Aproximación al conocimiento de la antijuricidad del hecho desde las teorías psicológicas del pensamiento intuitivo, Madrid, Dykinson, 2007, p. 89. 
lectual, o los límites de la libertad de cátedra, entre otras, de ahí que sea necesaria una formación de los docentes en determinados ámbitos para prevenir que se produzcan conductas alejadas de una clara intención en la vulneración de una norma.

El profesorado de los centros públicos tiene una serie de deberes que quedan recogidos en el Estatuto Básico del Empleado Público. Los artículos 52 (sobre deberes de los empleados públicos y código de conducta), 53 (principios éticos) y 54 (principios de conducta) del Real Decreto Legislativo 5/2015, de 30 de octubre, por el que se aprueba el texto refundido de la Ley del Estatuto Básico del Empleado Público, establece entre ellos los siguientes: velar por los intereses generales con sujeción y observancia de la Constitución y del resto del ordenamiento jurídico, actuar con objetividad, integridad, neutralidad, responsabilidad, imparcialidad, confidencialidad, dedicación al servicio público, transparencia, ejemplaridad, austeridad, accesibilidad, eficacia, honradez, etc.; el desempeño de las tareas correspondientes a su puesto de trabajo deben realizarse de forma diligente y cumpliendo la jornada y el horario establecidos; además deben obedecer las instrucciones y órdenes profesionales de sus superiores, salvo que estas constituyan una infracción manifiesta del ordenamiento jurídico, en cuyo caso las pondrán inmediatamente en conocimiento de los órganos de inspección procedentes. Del incumplimiento de estos deberes puede derivar un daño para la Administración Pública o para terceras personas, lo que fundamentaría el deber de reparar dicho daño.

La dificultad de la acción de repetición deriva de la determinación de la culpa o negligencia graves. Mientras que el dolo se puede definir como la conciencia y voluntad de realizar un daño, a sabiendas de su ilicitud, la culpa o negligencia graves resultan más problemáticas en su apreciación, en tanto que la persona que incurre en la misma no ha actuado en cuanto a lo que se esperaría de «un buen padre de familia», sino que no ha previsto - cuando debiera haberlo hecho- que su conducta llevaría parejo un daño, actuando lejos de toda prudencia y reflexión de forma voluntaria. Un claro ejemplo de culpa o negligencia graves sería la ausencia del profesor o profesora, aunque sea momentáneamente, en el momento y lugar donde se produce un hecho que genera un daño, como puede ser la manipulación de sustancias químicas en un laboratorio que comporten un peligro para la integridad física del alumnado, puesto que este comportamiento constituye una falta de previsión y vigilancia manifiesta.

En el dolo, en cambio, los daños derivan de una conducta intencionada de provocar una lesión, por lo que resultaría más fácil para 
la Administración el ejercicio de la acción de repetición por parte de la misma, puesto que esta no puede permitir y proteger la intencionalidad en la causación del daño por parte de uno de sus empleados. En este sentido, para Alicia Gil Gil ${ }^{14}$ el dolo tiene un carácter volitivo, si bien parte de la doctrina prescinde de dicho elemento y lo reducen al elemento intelectual, "con lo que para ellos el dolo sería solo conciencia de realizar el tipo objetivo». Por razones obvias el Derecho castiga con indemnizaciones de mayor cuantía las conductas dolosas porque se ha tenido intención de causar el daño, mientras que en la culpa o negligencia graves la indemnización se pondera en función de la responsabilidad de un daño producido por no haber puesto todos los medios para evitarlo.

Sin embargo, el problema de la aplicación de la acción de repetición dimana, en parte, de la difícil delimitación en la práctica de los conceptos de dolo, culpa o negligencia graves. En el caso del dolo, el docente debe tener un conocimiento exacto de la ilegalidad de su conducta, y además debe querer cometer esa ilegalidad, lo cual puede resultar difícil de demostrar. La culpa o negligencia graves, por su parte, derivan más de una conducta negligente, en tanto que el docente conoce que puede que de su conducta se derive una actuación antijurídica, pero cree que esta no producirá ningún daño a la Administración. La evaluación de una u otra conducta se determinará por los Tribunales de Justicia en aquellos procesos en los que declaran la responsabilidad patrimonial de los titulares de los centros y, en su caso, de la Administración Pública por los daños causados por las autoridades o personal a su servicio. Pero, como señala Ana Isabel Fortes ${ }^{15}$, «los conceptos elaborados en el ámbito civil y penal no son trasladables sin más al ámbito jurídico administrativo, sino que no podemos perder de vista que se deben aplicar en el ámbito del funcionamiento de los servicios públicos. Por ello sería conveniente la regulación de unos estándares mínimos de actuación que pudieran al menos orientar sobre si su incumplimiento pudiera ser considerado una negligencia grave». El problema es que siempre cabe el riesgo de que los encargados de enjuiciar el comportamiento de un docente, sea el titular del centro o un Tribunal, como doloso o culposo, consideren que la conducta puede calificarse como dolosa cuando en la realidad no haya sido así, y el docente deba hacer frente a una reparación de daños valorada subjetivamente.

14 GIL GIL, A. et alii, Curso de Derecho Penal. Parte General, Madrid, Dykinson, 2011, pág. 2018.

15 FORTES GONZÁLEZ, A. I., La responsabilidad patrimonial de las autoridades y personal al servicio de las Administraciones Públicas, Madrid, Instituto Nacional de Administración Pública, 2014, pág. 281. 


\section{CONSIDERACIONES SOBRE SU APLICACIÓN PRÁCTICA}

Como indica Javier Pérez Soriano, la incidencia de la acción de repetición en los centros docentes es muy pequeña, lo cual se debe básicamente a dos razones: porque resulta muy difícil el hecho de probar que la culpa en la que ha incurrido un determinado profesor o profesora pueda calificarse como grave, y porque «en la materialización de un accidente participan factores técnicos, organizativos, ambientales, etc., que son responsabilidad del titular de la actividad» ${ }^{16}$.

Muchos se han preguntado por las razones por las que la Administración Pública protege al funcionario hasta el punto de que nunca ejerce la acción de repetición, incluso en los casos de negligencia grave, y han reflexionado sobre lo injusto del hecho de que los contribuyentes deban costear con sus impuestos las indemnizaciones derivadas de daños acaecidos por imprudencias ajenas. Igualmente, merece una consideración la imagen que ofrece la Administración Pública cuando esta costea indemnizaciones millonarias por causa de la negligencia de un funcionario. A este respecto, entre los fundamentos destacados por Gabriel Doménech sobre la falta de ejercicio de la acción de regreso, alude a una causa que tradicionalmente se ha objetado, como es la evidencia de que con frecuencia las indemnizaciones a las que la Administración debe hacer frente sobrepasan en mucho el sueldo de un funcionario; este autor defiende que la Administración debería «exigir la reparación integral del daño, hasta donde lo permita el patrimonio del funcionario» ${ }^{17}$.

Un problema que derivaría de esta actuación por parte de la Administración sería un excesivo celo por parte de muchos docentes a la hora de llevar a cabo cualquier actividad que suponga un cierto riesgo, como puede ser la organización de las actividades extraescolares, que suponen una salida del centro docente y, por ende, conllevan un aumento del riesgo de que pueda ocurrir cualquier tipo de accidente que luego pudiera achacarse a imprudencia de la persona que ha organizado la misma o que acompaña al alumnado ${ }^{18}$. Y

16 Cfr. PÉREZ SORIANO, J., Manual de prevención docente. Riesgos laborales en el sector de la enseñanza, Valencia, Nau Llibres, 2009, pág. 112.

17 DOMÉNECH PASCUAL, G., "Por qué la Administración nunca ejerce la acción de regreso contra el personal a su servicio», Indret: Revista para el Análisis del Derecho, 2 (2008), pág. 11.

18 Para un estudio de sentencias del Alto Tribunal relacionadas con la responsabilidad patrimonial de la Administración en el ámbito educativo, véase el artículo de Carmen Delgado Moral, «La responsabilidad patrimonial de la Administración Pública en las actividades extraescolares y complementarias: sobre la jurisprudencia del Tribunal Supremo", Avances en supervisión educativa: Revista de la Asociación de Inspectores de Educación de España, 29 (2018), 1-26. 
es que el riesgo cero no existe, porque en cualquier actividad siempre alberga alguna posibilidad - por muy pequeña que sea- de que ocurra un accidente inesperado e indeseado. Cualquier práctica deportiva en clase de Educación Física o una actividad extraescolar soportan per se un riesgo inevitable, ya que ni la más estricta vigilancia por parte del profesorado puede evitar que un alumno tropiece y se caiga y de ello se derive un perjuicio para su salud. Por otro lado, una pequeña negligencia o descuido de un docente puede desencadenar un daño de gran magnitud; recuérdese, por ejemplo, la sentencia del Tribunal Supremo (Sala de lo Contencioso) de 15 de marzo de 2005 (Roj: STS 1621/2005), que declaró la responsabilidad de la Administración por el hecho de que un menor que había eludido momentáneamente la vigilancia a la que estaba sometido prendió fuego a un niño ocasionándole la muerte. El Alto Tribunal apreció que el accidente se había producido tanto por una desatención por parte de la progenitora del fallecido como por una falta de vigilancia (un descuido de consecuencias trágicas en este caso) de la cuidadora del otro menor, de ahí que procediera la indemnización de daños y perjuicios por responsabilidad patrimonial derivada del anormal funcionamiento de la Administración, al existir una relación de causalidad entre la prestación de servicios por parte de la Administración y el fallecimiento del menor.

\section{REFLEXIÓN SOBRE LO JUSTO DE SU (IN)APLICACIÓN}

Como dijo el Estagirita, «es sumamente importante que las leyes que están bien establecidas determinen, hasta donde sea posible, por sí mismas todo, y que dejen cuanto menos mejor al arbitrio de los que juzgan ${ }^{19}$, en tanto que las leyes se promulgan — como ya estableció el propio Aristóteles- tras dilatadas deliberaciones, al contrario que los juicios, a menudo tímidos e intempestivos. En este sentido, pues, corresponde a las leyes establecer lo justo (tò díkaion), dejando al enjuiciador todos los aspectos que el legislador dejó sin explicitar. En su concepción de la justicia como virtud, Aristóteles planteaba una teoría de la legislación que — como señala Jesús Vega - aunaba una filosofía práctica en la que las leyes juegan un papel fundamental «entre la ética y la política ${ }^{20}$; es en ese campo de la ética en el que valores como la igualdad, la seguridad o la digni-

${ }^{19}$ Cfr. ARISTÓTELES, Retórica, trad. Quintín Racionero, Madrid, Gredos, 2000, 1354a 32-34, pág. 30.

${ }^{20}$ VEGA LÓPEZ, J., «Legislación, racionalidad y argumentación en Aristóteles», Revista iberoamericana de argumentación, 13 (2006), pág. 3. 
dad, entre otros, cobran sentido y permiten entender determinadas actitudes por el principio de solidaridad y la congregación de intereses que subyace a ella.

Siguiendo la división tradicional establecida por el filósofo Paul Ricoeur en su célebre artículo "Ética y moral», la ética se concibe como «aspiración de una vida cumplida bajo el signo de las acciones estimadas buenas», frente a la moral, reservada "para el campo de lo obligatorio, marcado por las normas, las obligaciones, las prohibiciones, caracterizadas a la vez por una exigencia de universalidad y por un efecto de coerción ${ }^{21}$. Si bien el comportamiento de la Administración al no ejercer la acción de repetición puede parecer poco estético por inaplicación de una norma de carácter prescriptivo, una hipótesis sobre dicho comportamiento puede deberse a un cierto juicio ético por parte de la Administración sobre ese contenido valorativo derivado de la culpabilidad, y muy especialmente cuando atañe a la imprudencia.

El preámbulo de la Ley 19/2013, de 9 de diciembre, de transparencia, acceso a la información pública y buen gobierno apela a la responsabilidad de todos aquellos que desarrollan una actividad de relevancia pública, y alude a las consecuencias jurídicas que se derivarían de su incumplimiento. En el caso de un notorio quebrantamiento de las funciones inherentes a un determinado puesto de trabajo, la ley tipifica numerosas infracciones y establece las correspondientes sanciones. El Título II de la mencionada ley marca unos códigos éticos o de buen gobierno (transparencia, imparcialidad, diligencia en el cumplimiento de obligaciones, asunción de responsabilidades, etc.), en consonancia con su título, y que, si bien en su ámbito de aplicación se refiere «a los miembros del Gobierno, a los Secretarios de Estado y al resto de los altos cargos de la Administración General del Estado y de las entidades del sector público estatal, de Derecho público o privado, vinculadas o dependientes de aquella» (art. 25), fija unos principios éticos de actuación por los que debe regirse el personal dependiente de la Administración Pública y, lo que es más importante, eleva a mandato de ley unos mínimos pilares éticos que fundamentan la confianza del ciudadano hacia la Administración Pública y el personal a su servicio ${ }^{22}$.

${ }^{21}$ Cfr. RICOEUR, P., «Ética y moral», en Doce textos fundamentales de la ética del siglo XX (coord. Carlos Gómez), Madrid, Alianza, 2002, pág. 241.

${ }^{22}$ Para Fernando Irurzun, el cumplimiento de la norma y el comportamiento ético de los profesionales «repercute directamente sobre la imagen y reputación del conjunto del sistema de empleo público»; vid. IRURZUN MONTORO, F., «Ética y responsabilidad en la Administración Pública», Documentación administrativa, 286287 (2010), 79-111, espec. pág. 92. 
El Estatuto Básico del Empleado Público dedica treinta y siete artículos a los derechos de los empleados públicos y tan solo tres artículos a los deberes, lo cual evidencia una clara desproporción; en el primero de los deberes (art. 52) dispone nada menos que quince principios de actuación para los empleados públicos: «objetividad, integridad, neutralidad, responsabilidad, imparcialidad, confidencialidad, dedicación al servicio público, transparencia, ejemplaridad, austeridad, accesibilidad, eficacia, honradez, promoción del entorno cultural y medioambiental, y respeto a la igualdad entre mujeres y hombres ${ }^{23}$, estableciendo a continuación una distinción entre principios éticos, principios de conducta y principios rectores. Dichos principios se incardinan en el de buena administración ${ }^{24}$, como soporte básico de actuación del empleado público, y en manifiesta correspondencia con lo establecido en la Carta de Derechos Fundamentales de la Unión Europea ${ }^{25}$.

El ejercicio de la acción de repetición podrá aplicarse por parte de la Administración sin perjuicio de la responsabilidad disciplinaria que pueda reclamarse al docente cuando su actuación haya sido constitutiva de infracción administrativa, conforme a lo establecido en la correspondiente normativa sobre funcionarios y empleados públicos. Pero, puesto que la Administración tiene estos instrumentos, que puede aplicar o no sin necesidad de exigir una compensación económica al personal a su servicio - y más tratándose de casos en los que aquella sería inabarcable para el sueldo de un empleado público-, con la finalidad de que el ciudadano no conciba esta pasividad como producto de una «mala administración» se ve la necesidad de que se incoen expedientes disciplinarios cuando la actuación de un empleado público pueda ser calificada contraria a los principios de lealtad y buena fe con la Administración en la que el empleado presta su servicio, siempre que de ella se derive un perjuicio a los destinatarios finales del mismo: los administrados.

23 Vid. Real Decreto Legislativo 5/2015, de 30 de octubre, por el que se aprueba el texto refundido de la Ley del Estatuto Básico del Empleado Público, art. 52.

${ }^{24}$ Sobre este particular véase José Antonio Gámez Gámez, «El derecho a una buena administración desde la perspectiva de la ética pública: el buen gobierno y la buena conducta administrativa», en PENDÓN MUNOZ, F. y F. GUTIÉRREZ RODRÍGUEZ (coords.), El derecho de la ciudadanía a una buena administración: la administración electrónica, Diputación de Málaga, 2009, págs. 125-197.

${ }^{25} \mathrm{Vid}$. título V (Ciudadanía) de la Carta de Derechos Fundamentales de la Unión Europea, artículo 41 («Derecho a una buena administración»), tras la reforma operada en diciembre de 2007. 


\section{ACTUACIÓN VERSUS INACTIVIDAD ADMINISTRATIVA: UNA PROPUESTA DE ARMONIZACIÓN}

Cabe preguntarse si continuará in saecula saeculorum la inactividad de la Administración aquí abordada con respecto a la acción de repetición en el ámbito docente, y si sería positivo para la sociedad un cambio normativo que hiciese viable una aplicación de la ley en los casos en los que pudiera verificarse que la causación de un daño por parte de un trabajador del ámbito de la enseñanza ha sido provocada dolosamente, todo ello en aras de un cumplimiento efectivo de la ley que evite el desprestigio del aparato administrativo.

Sería lógico desde el punto de vista de la equidad un cambio en la norma para llevar a cabo una compensación de los gastos que hubiera podido ocasionar la conducta dolosa o imprudente por parte de un docente en el ejercicio de su actividad, de manera que la colectividad no se vea perjudicada por conductas reprobables que serían sancionadas en cualquier otro ámbito. Este cambio en la norma resultaría muy interesante para comprobar, pasado un tiempo, si se han producido cambios en el comportamiento del personal al servicio de la Administración en cuanto a conductas dolosas o culposas se refiere que originen indemnizaciones por responsabilidad patrimonial.

Por otro lado, para una aplicación eficaz de la acción de repetición resultaría oportuno minimizar los costes económicos —con una gradación de mínimos y máximos en relación al salario de los empleados- que acarrearían al funcionario la reparación de las indemnizaciones abonadas por la Administración, de forma que se eviten condenas que puedan suponer una deuda inabarcable para un trabajador de la Administración Pública, y suplirlas por sanciones dentro del ámbito disciplinario. Al igual que cuando un juez impone una condena satisface una necesidad social de protección hacia el ciudadano, la aplicación de una sanción disciplinaria como consecuencia de la acción de repetición a un docente por parte de la Administración supone velar por los intereses generales, a cuya satisfacción deben orientarse las actuaciones de la misma. No obstante, para la aplicación de una sanción administrativa es necesario, al igual que ocurre en el Derecho Penal, que la acción u omisión que ha dado su origen sea típica, antijurídica y culpable, como ya lo expresara la Sentencia del Tribunal Supremo de 23 de febrero de 2000:

"son transplantables, con ciertos matices, al ámbito de la potestad sancionadora de la Administración los principios que rigen el Derecho Penal, al ser ambos campos manifestaciones de la potestad punitiva del 
Estado. Conforme a ellos para que una determinada acción u omisión pueda ser objeto de sanción es necesario que sea típica, antijurídica y culpable; presupuestos que quedan eliminados por la concurrencia de causas de justificación, o excluyentes de la culpabilidad o antijurisdicidad» ${ }^{26}$.

Como indica Belén Marina, la naturaleza fiduciaria de la Administración y los agentes públicos a su servicio deriva en la necesidad de garantizar una serie de conductas caracterizadas «por el deber de fidelidad, del que derivan exigencias de diverso contenido pero que, sintéticamente, puede resumirse en la obligación de no perjudicar los intereses de la organización ${ }^{27}$. Quizá sea necesaria una mejora en la eficiencia del sistema funcionarial, lo que requiere un estudio de las medidas que incentiven un comportamiento de este tipo de empleados similar al que encontramos en el sector privado.

\section{CONCLUSIONES}

La actual configuración de la responsabilidad patrimonial de la Administración Pública prescribe que esta repercuta sobre los empleados públicos causantes de un daño cuando exista dolo, culpa o negligencia graves, siempre que se dé una serie de requisitos previos: por un lado, que el particular afectado haya promovido un procedimiento de responsabilidad patrimonial contra la Administración, y, por otro, que la Administración haya procedido al abono de la indemnización una vez reconocida una reparación económica del daño objetivo mediante resolución administrativa no impugnada o a través de sentencia judicial firme.

El hecho de que la acción de regreso no haya sido nunca aplicada por la Administración en el ámbito que nos ocupa, pese a las diversas modificaciones introducidas por la normativa en un vano intento de soslayar su tradicional inactividad en este asunto, deviene en un reto para la propia Administración y a la vez en un desafío de la misma, en tanto que su actuación contraviene cualquier principio de lógica jurídica. Cabría preguntarse qué pasará el día en que la acción de regreso se ponga en práctica, y cómo afectará al ejercicio docente; en tanto que en el desarrollo de las actividades escolares y, sobre todo, extraescolares acaecen multitud de situaciones en las que el riesgo cero simplemente no existe, el ejercicio de esta acción de repetición

${ }^{26}$ Sentencia del Tribunal Supremo, Sala de lo Contencioso, de 23 de febrero de 2000 (ROJ: STS 1375/2000), Fundamento de derecho cuarto.

27 MARINA JALVO, B., El régimen disciplinario de los empleados públicos (Fundamentos y regulación sustantiva), Valladolid, Lex Nova, 2006, pág. 29. 
podría conllevar el recelo por parte del docente a realizar determinados tipos de actividades con el alumnado, al ser consciente de que una decisión adoptada ante un peligro en una determinada situación crítica pueda verse luego como una actitud negligente. Además, la hipotética aplicación de esta acción de repetición contra docentes de la Administración Pública podría verse como una discriminación por parte del docente afectado, el cual podría calificar la actuación de la Administración como absolutamente discrecional.

Esa trayectoria histórica de inaplicación de una norma, cuyo contenido se ha visto sustituido por una solidaridad de la Administración con sus propios empleados, puede concebirse desde un punto de vista ético como salvaguarda de un colectivo que trabaja para el bien común.

Para la prevención de actuaciones por parte del profesorado que sean contrarias tanto al principio de buena fe como a las normas de nuestro ordenamiento jurídico, sería beneficiosa una preparación del profesorado en responsabilidad civil y una formación en prevención de riesgos que pudieran derivar en un daño antijurídico.

\section{BIBLIOGRAFÍA}

ARISTÓTELes, Retórica, trad. Quintín Racionero, Madrid, Gredos, 2000.

BARCELONA Llop, J., «La acción de regreso en la Ley de Régimen Jurídico de las Administraciones Públicas y del Procedimiento Administrativo Común», Revista Española de Derecho Administrativo (REDA), 105 (2000).

BARCELONA Llop, J., «La acción de regreso en la Ley de Régimen Jurídico de las administraciones públicas y del procedimiento administrativo común", en VV.AA., Homenaje a Luis Rojo Ajoria: escritos jurídicos, Universidad de Cantabria, 2003, págs. 765-784.

Beltrán Flores, L., "¿Crecimiento indefinido del Sector Público?», Papeles de economía española, 7 (1981), 130-135.

Blanguer, D., La responsabilidad patrimonial de las Administraciones Públicas, Madrid, Instituto Nacional de Administración Pública, 1997.

Carro Fernández-Valmayor, J. L., «Ética pública y normativa administrativa», Revista de administración pública, 181 (2010), 9-37.

Carta de los Derechos Fundamentales de la Unión Europea, Diario Oficial de las Comunidades Europeas, 2007. 
Collado Martínez, R., «Algunas notas sobre la responsabilidad patrimonial en las Leyes 39/2015, de 1 de octubre, del Procedimiento Administrativo Común de las Administraciones Públicas y 40/2015, de 1 de octubre, de Régimen Jurídico del Sector Público», Asamblea: revista parlamentaria de la Asamblea de Madrid, 34 (2016), 155-196.

Consejo de Estado. Dictamen de Consejo de Estado n. ${ }^{\circ}$ 5356/1998 de 22 DE ENERO DE 1998, sobre «Anteproyecto de Ley de Modificación de la Ley 30/92, 26 de noviembre, de régimen jurídico de las Administraciones Públicas y del procedimiento administrativo común».

Cuesta Aguado, P. M. de la, Conocimiento de la ilicitud. Aproximación al conocimiento de la antijuricidad del hecho desde las teorías psicológicas del pensamiento intuitivo, Madrid, Dykinson, 2007.

Delgado Moral, C., «La responsabilidad patrimonial de la Administración Pública en las actividades extraescolares y complementarias: sobre la jurisprudencia del Tribunal Supremo», Avances en supervisión educativa: Revista de la Asociación de Inspectores de Educación de España, 29 (2018), 1-26.

DíAz MADrera, B., La responsabilidad patrimonial de la Administración en el ámbito educativo, Madrid, Reus, 2007.

DíEz SÁNCHEZ, J. J., "Las acciones de regreso contra autoridades y funcionarios públicos», en La responsabilidad civil y su problemática actual (coord. Antonio Moreno Martínez), Madrid, Dykinson, 2007, págs. 205-234.

Doménech Pascual, G., «Por qué la Administración nunca ejerce la acción de regreso contra el personal a su servicio", Indret: Revista para el Análisis del Derecho, 2 (2008), 1-20.

Fortes GonZÁLEZ, A. I., La responsabilidad patrimonial de las autoridades y personal al servicio de las Administraciones Públicas, Madrid, Instituto Nacional de Administración Pública, 2014.

Frank, R., Sobre la estructura del concepto de culpabilidad, Montevideo-Buenos Aires, Editorial B de f, 2002.

Gálvez Arenas, M. J., Responsabilidad civil y penal del personal docente respecto a los menores a su cargo, Sevilla, Universidad Internacional de Andalucía, 2012.

GÁmez GÁmez, J. A., «El derecho a una buena administración desde la perspectiva de la ética pública: el buen gobierno y la buena conducta administrativa», en El derecho de la ciudadanía a una buena administración: la administración electrónica, Diputación de Má- 
laga (coords. F. Pendón Muñoz y F. Gutiérrez Rodríguez), 2009, págs. 125-197.

GIL GIL, A., J. M. Lacruz López, M. Melendo Pardos y J. Núñez Fernández, Curso de Derecho Penal. Parte General, Madrid, Dykinson, 2011.

IrURzun MonToro, F., «Ética y responsabilidad en la Administración Pública», Documentación administrativa, 286-287 (2010), 79-111.

LuZón PeÑa, D. M., «Libertad, culpabilidad y neurociencias», Indret: Revista para el Análisis del Derecho, 3 (2012), 1-59.

Marina Jalvo, B., El régimen disciplinario de los empleados públicos (Fundamentos y regulación sustantiva), Valladolid, Lex Nova, 2006.

PéRez Soriano, J., Manual de prevención docente. Riesgos laborales en el sector de la enseñanza, Valencia, Nau Llibres, 2009.

Ricoeur, P., «Ética y moral», en Doce textos fundamentales de la ética del siglo XX (coord. C. Gómez, 2002), págs. 241-255.

SAURA Fructuoso, C., «La ignota acción de regreso de la administración en la era de la transparencia, la eficiencia y la responsabilidad», Documentación Administrativa: Nueva Época, 2 (2015).

VEGA LÓPEZ, J., «Legislación, racionalidad y argumentación en Aristóteles», Revista iberoamericana de argumentación, 13 (2006), 39 págs. 